\title{
Avaliação Ecotoxicológica do Agrotóxico Lambda Cialotrina para Hydra attenuata
}

\section{Vivien Mori, Francine I. Vacchi, Gisela A. Umbuzeiro}

\section{Resumo}

A exposição de agrotóxicos pode levar a efeitos adversos nos organismos não alvos, entre eles, espécies aquáticas. Dentre os vários tipos de agrotóxicos aprovados para uso no Brasil, selecionamos para o estudo a lambda cialotrina utilizada como inseticida. Já existem dados na literatura sobre estudos toxicológicos com peixes, algas e crustáceos, porém não foram encontradas informações toxicológicas com cnidários. Cnidários são consumidores secundários e já existem protocolos que permitem sua utilização como organismo teste em laboratórios.

\section{Palavras-chave:}

piretroide, inseticida, cnidários.

\section{Introdução}

O uso de agrotóxicos na agricultura para o controle de pragas e eventuais regulamentações pouco protetivas no que se refere a proteção do meio ambiente pode levar aos efeitos indesejados como perda de biodiversidade no ambiente aquático. O presente projeto tem por objetivo analisar os efeitos agudos e sub letais com a Hydra attenuata, um cnidário de água doce para complementar os dados existentes na literatura, ampliando assim, as bases de conhecimento e os possíveis efeitos do agrotóxico lambda cialotrina, uma nova geração de piretroides sintéticos do tipo II, à biota aquática.

\section{Resultados e Discussão}

A faixa de concentração utilizada teve sua maior concentração obedecendo o limite de solubilidade da substância. Os resultados indicaram que até o limite de solubilidade da lambda cialotrina, essa não apresentou qualquer efeito sub letal ou letal para a Hydra. Ao final do teste, os parâmetros de condutividade e $\mathrm{pH}$ se mantiveram em ótima condição.

Os dados sobre a toxicidade da lambda cialotrina com organismos aquáticos e terrestres estão resumidos nas Tabelas 1 e 2.

Tabela 1 - Dados de toxicidade da lambda cialotrina para

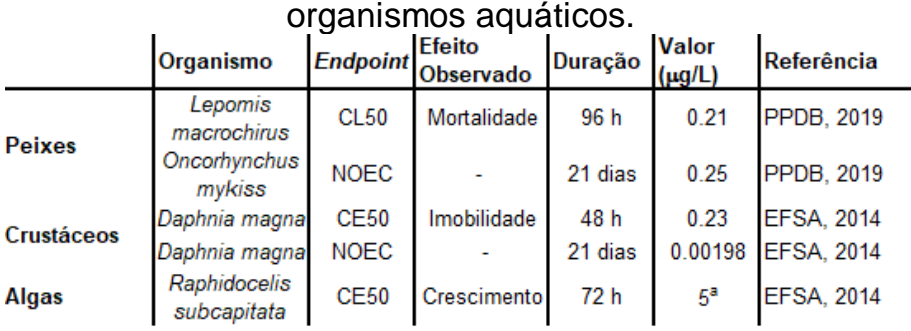

Tabela 2 - Dados de toxicidade da lambda cialotrina para organismos aquáticos.

\begin{tabular}{l|c|c|c|c|c|c} 
& Organismo & Endpoint & $\begin{array}{l}\text { Efeito } \\
\text { Observado }\end{array}$ & Duração & Valor $(\mathbf{m g} / \mathbf{k g})$ & Referência \\
\hline \multirow{3}{*}{ Mamiferos } & $\begin{array}{c}\text { Rattus } \\
\text { norvegicus } \\
\text { Rattus } \\
\text { norvegicus }\end{array}$ & NOAEL & $\begin{array}{c}\text { Mudança de } \\
\text { peso }\end{array}$ & 90 dias & 50 & EPA, 1997 \\
Colinus & LOAEL & - & 90 dias & 250 & EPA, 1997 \\
Oligoqueta & DL50 & - & 5 dias & $>5300$ & EPA, 1997 \\
& $\begin{array}{c}\text { Mallard duck } \\
\text { Eisenia } \\
\text { foetida corr }\end{array}$ & DL50 & - & 5 dias & 3948 & EPA, 1997 \\
& DL50 & - & 14 dias & $>500$ & PPDB, 2019
\end{tabular}

O mecanismo de ação dos piretróides, como a lambda cialotrina é a interação com os canais de sódio neuronais. No caso da $H$. attenuata, o organismo apresenta um sistema nervoso difuso de condução lenta composto por células nervosas sem diferenciações ou especializações. Isso pode explicar o fato da lambda cialotrina não apresentar efeitos agudos no organismo em estudo.

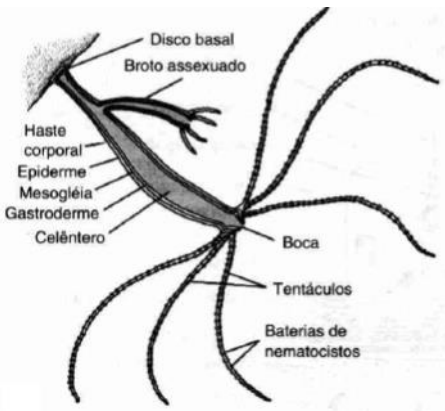

Figura 1. Estrutura básica da Hydra attenuata. Fonte: Barnes, 1984.

\section{Conclusões}

Concluímos que a lambda cialotrina não apresentou efeitos letais ou sub letais em testes agudos realizados com a Hydra attenuata até o limite de solubilidade do composto. O resultado obtido neste trabalho complementa os dados da literatura sobre os efeitos adversos causados pelo agrotóxico estudado em cnidários.

\section{Agradecimentos}

Ao Laboratório de Ecotoxicologia e Genotoxicidade (LAEG) pela disponibilidade dos dados e organismos utilizados para a pesquisa.

BARNES, R.D. Zoologia de invertebrados. 4를 ed. São Paulo: Rocca, 1984 104-111 p.

EUROPEAN FOOD SAFETY AUTHORITY, EFSA. Conclusion on the peer review of the pesticide risk assessment of the active substance lambda-cyhalothrin. EFSA Journal, 2014. Parma, Itália, 2015.

ENVIRONMENTAL PROTECTION PROGRAM, EPA. Ecological Effects Branch Review - Lambda cialotrina (KARATE). 1997.

PESTICIDE PROPERTIES DATABASE, PPDB. The University of

Hertfordshire Agricultural Substances Database: Background and

Support Information. University of Hertfordshire. 2019. 